\title{
MOBILE APPLICATION UNTUK PROGRAM DIET OBESITAS \& OVERWEIGHT : TINJAUAN PUSTAKA
}

\author{
Caecilia Titin Retnani ${ }^{1}$, La Ode Abd Rahman ${ }^{2}$ \\ ${ }^{1}$ Mahasiswa Program Pasca Sarjana Peminatan Komunitas, \\ Fakultas Ilmu Keperawatan Universitas Indonesia. \\ Korespondensi penulis, e-mail: titin.retnani@yahoo.com \\ ${ }^{2}$ Dosen Fakultas Ilmu Keperawatan, Universitas Indonesia
}

\begin{abstract}
ABSTRAK
Kejadian overweight dan obesitas semakin meningkat terutama pada usia $18-60$ tahun. Berdasarkan WHO (World Health Organization) tahun 2016 semakin banyak usia dewasa mengalami obesitas. Dampak kesehatan akibat dari overweight dan obesitas adalah penyakit tidak menular. Salah satu cara mengatasi obesitas menggunakan teknologi berbasis internet yaitu mobile application. Penelitian ini menggunakan metode Tinjauan Pustaka (Literatur Review), database yang digunakan ScienceDirect, ProQuest, Biomedcentral.com, NCBI tahun 2015-2019. Beberapa tinjauan pustaka memaparkan kefektifan penggunaan m-health dalam menurunkan berat badan. Beberapa aplikasi yang bisa dipakai adalah CHAT, MyFitnessPal App, Vegheton. Aplikasi ini berisikan informasi manajemen pola makan, berisikan gambar menu diet, pemantauan diet mandiri, umpan balik dari kegiatan pola makan. Didapatkan jika perlunya penelitian lebih lanjut dalam penerapan teknologi $m$-health dalam memanajemen klien dengan obesitas sehingga bisa digunakan dalam jangkauan yang luas.
\end{abstract}

Kata kunci : mobile application, diet, obesitas, overweight

\section{LATAR BELAKANG}

Perkembangan masalah kesehatan saat ini beragam pada remaja dan dewasa, mulai dari kekurangan berat badan (underweight) sampai overweight dan obesitas. Data WHO (World Health Organization) tahun 2016 menunjukan bahwa lebih dari 1,9 miliyar, dewasa usia 18 tahun dan lebih tua mengalami overweight dan lebih dari 650 juta mengalami obesitas (WHO, 2018). Negara Indonesia tahun 2018 proporsi obesitas pada usia 18 tahun keatas (dewasa) 21,8 \% (RISKESDAS, 2018). Proporsi overweight (kelebihan berat badan) dari tahun 2013 sebesar 11,5\% naik pada tahun 2018 sebesar 13,6\%. Sedangkan untuk proporsi obesitas pada tahun 2013 14,8 \% naik menjadi 21, $8 \%$ pada tahun 2018(RISKESDAS, 2018).

Efek negatif yang ditimbulkan dari obesitas dan kelebihan berat badan (overweight) adalah terjadinya penyakit tidak menular (non communicable diseases). Beberapa contoh penyakit tidak menular, penyakit kardiovaskuler yang dapat menyebabkan kematian, ditunjukan pada tahun 2017 sekitar 41 juta (73\%) penduduk meninggal pada usia 
dibawah 70 tahun (WHO, 2019). Selain penyakit jantung, yaitu gangguan mukuloskeletal yaitu osteoatritis, kanker.

Penyakit tersebut dapat dicegah dari faktor resikonya dengan diet yang sehat dan aktivitas fisik. Diet yang sehat dapat berupa mengurangi konsumsi kalori, garam , memperbanyak sayur dan buahbuahan (WHO, 2018). Oleh karena itu perlu adanya kegiatan promosi kesehatan agar kejadian overweight dan obesitas tidak semakin naik perlu adanya promosi kesehatan berinovasi dengan berbasis teknologi. Dalam perkembangan teknologi saat ini yang sudah masuk dalam area industry 4.0, merupakan perkembangan industri berbasis internet (Sindu, 2018).

Berbagai macam aplikasi dalam bidang kesehatan diciptakan. Salah satunya adalah mobile application yang digunakan untuk pengaturan diet klien, terutama dewasa. Berdasarkan data pemakai smartphone usia 18-34 tahun, naik dari $39 \%$ menjadi $66 \%$ dari tahun 2015-2018, dari usia dewasa kepemilikan smartphone 42\%, smartphone biasa $28 \%$, tidak memiliki smartphone 29\% (Yanuar, 2019). Sehingga diharapkan dengan adanya media promosi kesehatan berbasis mobile application dapat membantu menurunkan angka kejadi overweight dan obesitas.

\section{METODE}

Metode yang digunakan dalam pembuatan penelitian ini adalah Tinajaun Pustaka (Literature Review), yaitu mencari berbagai macam artikel selanjutnya ditelaah untuk mencari informasi yang diinginkan. Pencariaan artikel menggunakan kata kunci, obesity, dietary, $m$-Health for obesity, adult and obesity. Sumber database artikel yang didapatkan melalui
ScienceDirect, ProQuest, Biomedcentral.com, NCBI (National Centre for Biotechnology Information, sumber yang dicari dalam rentang tahun 2015-2019.

\section{TINJAUAN PUSTAKA}

Mobile Application ( aplikasi handphone) merupakan software yang termasuk dalam teknologi mobile health dengan menggunakan internet yang bertujuan untuk meningkatkan perilaku kesehatan, pelayanan perawatan kesehatan, dan penelitian kesehatan (Hingle \& Patrick, 2016). Dalam artikel perspektif yang dibuat oleh Higle dan Patrick memaparkan bahwa keefektifan menggunakan mobile application untuk mengubah perilaku, salah satu contohnya adalah perilaku pengaturan pola makan masih relatif. Fungsi mobile application tergantung dari aplikasinya, penampilan yang menarik dari software, kredibilitas, rating yang didapat dari aplikasi tersebut, serta belum ada cara yang jelas dalam melakukan evaluasi dari penggunaan mobile application. Oleh karena perlu adanya penelitian lebih lanjut untuk melihat keefektifan dalam mengubah perilaku (Hingle \& Patrick, 2016).

Penelitian yang lain berupa evaluasi dari penggunaan mobile application yaitu, penelitian penggunaan mobile application berupa catatan makan di handphone dan pesan teks untuk mengubah perilaku pola makan pada usia dewasa muda (18-30 tahun) . Tujuan dilakukan studi ini mengevaluasi efektivitas umpan balik pada diet khusus dalam bentuk teks mingguan yang dikirimkan agar dapat meningkatkan pola makan yang baik. Hasil menunjukan kelompok yang diberikan umpan balik terjadi penurunan berat badan sebanyak 1,7 $\mathrm{kg}$, dengan laki-laki ada penurunan 
konsumsi EDPN (Energy Dense Nutrient Poor) sebanyak 1,4 persajian/hari, dan wanita mengurangi konsumsi gula 0,2 persajian/hari. Berdasarkan data tersebut penggunaan umpan balik dengan mobile application sangat bagus dan potensial dalam memberikan promosi kesehatan dalam program diet (Kerr et al., 2016).

Sejalan dengan penelitian yang dilakukan oleh Mummah et al., (2017) tentang penggunakan mobil aplikasi dalam mengkonsumsi sayuran pada klien dewasa (18-50 tahun) dengan overweight menghasilkan adanya peningkatan konsumsi sayur dari sebelum perlakuan sampai setelah

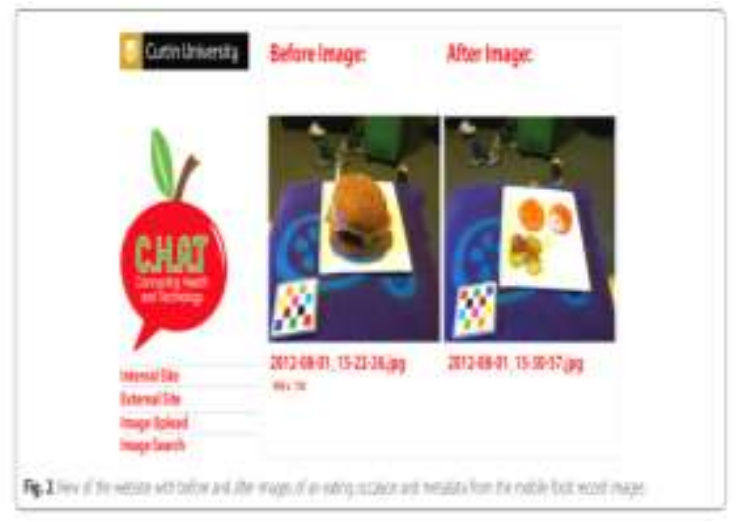

Gambar 1. Mobile

Application untuk diet

“CHAT"(Kerr et al., 2016)

Hasil penelitian lain yang memberikan paparan keefektifan mobile application dalam mengatur diet, yaitu (Ipjian \& Johnston, 2017) dengan penelitian tentang teknologi smartphone dalam memfasilitasi perubahan diet pada usia dewasa muda. Cara kerja dari smartphone ini memberikan edukasi untuk menurunkan konsumsi garam menggunakan apalikasi MyFitnessPal App dan mendapatkan umpan balik perlakukan. Berdasarkan hasil tersebut menunjukan bahwa dengan menggunakan mobile application yang berbasis teori dapat meningkatkan konsumsi sayuran pada orang dewasa dengan masalah kelebihan berat badan. Intervensi mobile application ini berbasis teori, yang memberikan biaya yang murah, terukur, dan efektif dalam meningkatkan perilaku diet dan mencegah penyakit kronis (Kerr et al., 2016). Berikut salah satu gambar mobile application untuk membantu pengaturan makan atau diet.

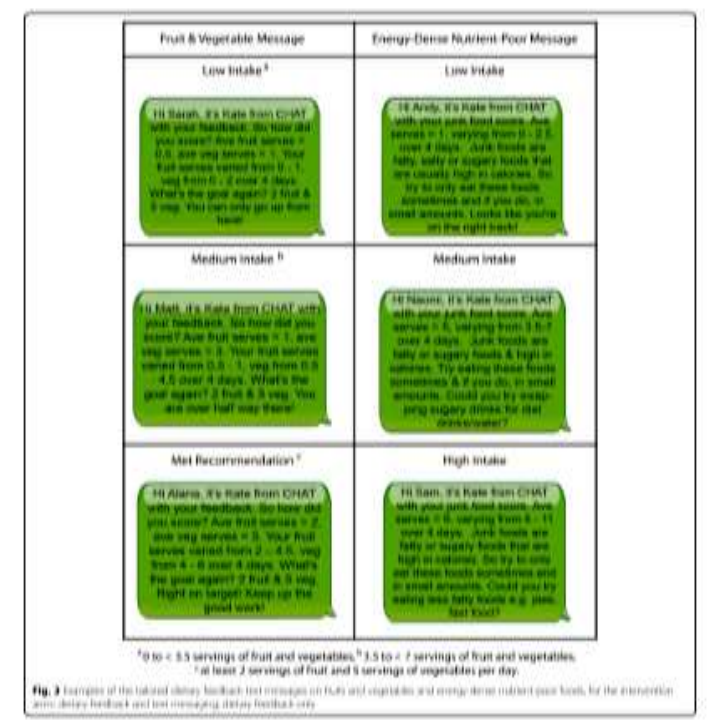

Gambar 2. Umpan Balik dalam intervensi penggunaan aplikasi

(Kerr et al., 2016)

tentang kadar garam dalam tubuh. Hasil penelitian ini memberikan kesimpulan mobile application sukses dalam meningkatkan kesehatan dengan melihat tanda biologis yaitu kandungan garam dalam urine (Ipjian \& Johnston, 2017).

Selain itu penelitian yang lain yang digunakan dalam pengaturan pola makan pada usia 18-65 tahun yaitu oleh (Turner-McGrievy et al., 2019), penelitian ini tentang metode pemantauan pola makan secara 
mandiri menggunakan mobile application, yang bertujuan untuk memberikan penilaian objektif terhadap kepatuhan diri sendiri dalam mengatur pola makan. Aplikasi ini menilai kepatuhan klien secara mandiri sehingga dengan penilaian ini dapat memberikan efek pola makan yang baik sehingga dapat memberikan prediksi terjadinya penurunan berat badan. Cara kerja aplikasi ini memberikan keyakinan dengan memberikan informasi cara menurunkan berat badan, dengan cara selama dua minggu mengirimkan informasi ke Podcast sebanyak dua kali seminggu. Hasil yang ditunjukan adalah dengan mengkonsumsi makan dua kali sehari banyak terjadi variasi penurunan berat badan. Dengan data tersebut penggunaan aplikasi pada seluler untuk memantau pola makan secara mandiri menjadi cara terbaik untuk melihat kepatuhan diri dalam program diet (Turner-McGrievy et al., 2019). 
HASIL

Berikut merupakan jurnal-jurnal pilihan yang peneliti analisis dalam studi literature review ini:

Tabel 1. Rincian Hasil Jurnal Pilihan Utama untuk Literature Review

\begin{tabular}{|c|c|c|c|c|c|c|}
\hline No & $\begin{array}{c}\text { Penulis/ } \\
\text { Tahun }\end{array}$ & $\begin{array}{c}\text { Judul } \\
\text { Penelitian }\end{array}$ & $\begin{array}{l}\text { Nama } \\
\text { Jurnal }\end{array}$ & $\begin{array}{c}\text { Tujuan } \\
\text { Penelitian }\end{array}$ & $\begin{array}{c}\text { Metode } \\
\text { Penelitian }\end{array}$ & Hasil Penelitian \\
\hline 1. & $\begin{array}{l}\text { (Hingle } \\
\& \\
\text { Patrick, } \\
\text { 2016) }\end{array}$ & $\begin{array}{l}\text { There Are } \\
\text { Thousands } \\
\text { of Apps for } \\
\text { That: } \\
\text { Navigating } \\
\text { Mobile } \\
\text { Technology } \\
\text { for Nutrition } \\
\text { Education } \\
\text { and } \\
\text { Behavior } \\
\text { Melanie }\end{array}$ & $\begin{array}{l}\text { Journal of } \\
\text { Nutrition } \\
\text { Education } \\
\text { and } \\
\text { Behavior }\end{array}$ & $\begin{array}{l}\text { Mengeksplorasi } \\
\text { kapan dan untuk } \\
\text { siapa pendekatan } \\
\text { mHealth dapat } \\
\text { efektif, melihat } \\
\text { kekuatan dan } \\
\text { keterbatasan dari } \\
\text { aplikasi yang } \\
\text { dihasilkan secara } \\
\text { komersial, } \\
\text { akademis, } \\
\text { pertimbangan } \\
\text { desain penelitian } \\
\text { dan kemitraan } \\
\text { publik swasta }\end{array}$ & $\begin{array}{l}\text { Perspective } \\
\text { Article }\end{array}$ & $\begin{array}{l}\text { 1. Saat ini tidak } \\
\text { ada referensi } \\
\text { standar yang } \\
\text { digunakan } \\
\text { untuk } \\
\text { pemilihan } \\
\text { aplikasi yang } \\
\text { cocok untuk } \\
\text { pengaturan } \\
\text { diet (pola } \\
\text { makan) } \\
\text { responden. } \\
\text { 2. Aplikasi } \\
\text { seharusnya } \\
\text { memiliki } \\
\text { pengaruh } \\
\text { yang } \\
\text { potensial, } \\
\text { yang } \\
\text { idealnya } \\
\text { harus } \\
\text { melalui } \\
\text { evidance } \\
\text { based } \\
\text { practice, } \\
\text { memiliki } \\
\text { features, } \\
\text { fungsi dan } \\
\text { kerangka } \\
\text { intervensiny } \\
\text { a. }\end{array}$ \\
\hline 2. & $\begin{array}{l}\text { (Ipjian } \\
\& \\
\text { Johnston } \\
\text {, 2017) }\end{array}$ & $\begin{array}{l}\text { Smartphone } \\
\text { Technology } \\
\text { Facilitates } \\
\text { Dietary } \\
\text { Change in } \\
\text { Healthy } \\
\text { Adults }\end{array}$ & $\begin{array}{l}\text { Journal } \\
\text { Nutrition }\end{array}$ & $\begin{array}{l}\text { Memodifikasi } \\
\text { single dietary, } \\
\text { penurunan } \\
\text { konsumsi garam, } \\
\text { untuk } \\
\text { menentukan } \\
\text { aplikasi kesehatan } \\
\text { berguna untuk } \\
\text { mempromosikan }\end{array}$ & $\begin{array}{l}\text { Randomize } \\
\text { Control Trial }\end{array}$ & $\begin{array}{l}\text { 1. Peserta } \\
\text { kelompok } \\
\text { aplikasi } \\
\text { melaporkan } \\
\text { kepuasan } \\
\text { yang besar } \\
\text { secara } \\
\text { signifikan } \\
\text { dengan } \\
\end{array}$ \\
\hline
\end{tabular}




\begin{tabular}{|c|c|c|c|c|c|c|}
\hline & & & kesehatan & & 2. & $\begin{array}{l}\text { metode } \\
\text { pelacak diet } \\
\text { daripada } \\
\text { kelompok } \\
\text { jurnal } \\
\text { (kontrol) } \\
\text { Data } \\
\text { menunjukan } \\
\text { aplikasi } \\
\text { smartphone } \\
\text { memiliki } \\
\text { potensial } \\
\text { fasilitas } \\
\text { dalam } \\
\text { pengaturan } \\
\text { program diet }\end{array}$ \\
\hline $\begin{array}{ll}\text { 3. } & \text { (Kerr et } \\
\text { al., } \\
\text { 2016) }\end{array}$ & $\begin{array}{l}\text { The } \\
\text { Connecting } \\
\text { Health And } \\
\text { Technology } \\
\text { Study: A 6- } \\
\text { Month } \\
\text { Randomized } \\
\text { Controlled } \\
\text { Trial To } \\
\text { Improve } \\
\text { Nutrition } \\
\text { Behaviours } \\
\text { Using A } \\
\text { Mobile Food } \\
\text { Record And } \\
\text { Text } \\
\text { Messaging } \\
\text { Support In } \\
\text { Young Adults }\end{array}$ & $\begin{array}{l}\text { Internatio } \\
\text { nal } \\
\text { Journal of } \\
\text { Behavioral } \\
\text { Nutrition } \\
\text { and } \\
\text { Physical } \\
\text { Activity }\end{array}$ & $\begin{array}{l}\text { Melihat hubungan } \\
\text { kesehatan dengan } \\
\text { teknologi untuk } \\
\text { mengevaluasi } \\
\text { keefektifan } \\
\text { umpan balik } \\
\text { makanan khusus } \\
\text { dan pesan teks } \\
\text { mingguan untuk } \\
\text { meningkatkan } \\
\text { asupan sayur dan } \\
\text { buah selama } 6 \\
\text { minggu pada } \\
\text { sampel pria dan } \\
\text { wanita berbasis } \\
\text { populasi dengan } \\
\text { usia 18-30 tahun. }\end{array}$ & $\begin{array}{l}\text { Randomize } \\
\text { Controll Trial }\end{array}$ & 1. & $\begin{array}{l}\text { Umpan balik } \\
\text { diet yang } \\
\text { disesuaikan } \\
\text { hanya } \\
\text { menghasilka } \\
\text { n penurunan } \\
\text { makanan } \\
\text { EDNP } \\
\text { (Energy } \\
\text { Dense } \\
\text { Nutrient } \\
\text { Poor) pada } \\
\text { pria dan SSB } \\
\text { (Sugar } \\
\text { Sweetened } \\
\text { Baverage) } \\
\text { pada wanita } \\
\text { secara } \\
\text { bersamaan } \\
\text { dengan } \\
\text { penurunan } \\
\text { berat badan } \\
\text { Menggunaka } \\
\text { n catatan } \\
\text { makanan } \\
\text { seluler untuk } \\
\text { penilaian } \\
\text { diet dan } \\
\text { umpan balik } \\
\text { yang } \\
\text { disesuaikan } \\
\text { sangat bagus }\end{array}$ \\
\hline
\end{tabular}




\begin{tabular}{|c|c|c|c|c|c|c|c|}
\hline & & & & & & & $\begin{array}{l}\text { dan potensial } \\
\text { untuk } \\
\text { intervensi } \\
\text { promosi } \\
\text { kesehatan di } \\
\text { masa depan } \\
\text { yang } \\
\text { menargetkan } \\
\text { diet dan } \\
\text { berat badan } \\
\text { pada orang } \\
\text { dewasa } \\
\text { muda }\end{array}$ \\
\hline 4. & $\begin{array}{l}\text { (Lieffers } \\
\text { Arocha, } \\
\text { Grindro } \\
\text { d, \& } \\
\text { Hanning } \\
\text {, 2018) }\end{array}$ & $\begin{array}{l}\text { Experiences } \\
\text { and } \\
\text { Perceptions of } \\
\text { Adults } \\
\text { Accessing } \\
\text { Publicly } \\
\text { Available } \\
\text { Nutrition } \\
\text { Behavior- } \\
\text { Change } \\
\text { Mobile Apps } \\
\text { for } \\
\text { Weight } \\
\text { Management }\end{array}$ & $\begin{array}{l}\text { Journal of } \\
\text { the } \\
\text { academy } \\
\text { of } \\
\text { nutrition } \\
\text { and } \\
\text { dietetics }\end{array}$ & $\begin{array}{l}\text { Memahami } \\
\text { pengalaman dan } \\
\text { persepsi } \\
\text { responden dewasa } \\
\text { yang telah } \\
\text { menggunakan } \\
\text { aplikasi seluler } \\
\text { yang tersedia } \\
\text { untuk umum agar } \\
\text { mendukung } \\
\text { perubahan } \\
\text { perilaku gizi } \\
\text { untuk } \\
\text { memanajemen } \\
\text { berat badan }\end{array}$ & $\begin{array}{l}\text { Qualitative } \\
\text { research }\end{array}$ & & $\begin{array}{l}\text { Aplikasi } \\
\text { telah } \\
\text { menjadi alat } \\
\text { yang } \\
\text { menarik dan } \\
\text { utama untuk } \\
\text { membantu } \\
\text { individu } \\
\text { dalam } \\
\text { meningkatka } \\
\text { n perilaku } \\
\text { makan } \\
\text { bergizi } \\
\text { Beberapa } \\
\text { responden } \\
\text { mengatakan } \\
\text { mereka } \\
\text { merasa } \\
\text { terbantu } \\
\text { dalam } \\
\text { memenajem } \\
\text { en } \\
\text { penurunan } \\
\text { berat badan } \\
\text { Beberpa } \\
\text { responden } \\
\text { berhenti } \\
\text { menggunaka } \\
\text { n aplikasi } \\
\text { karena } \\
\text { mengalamai } \\
\text { kesulitan } \\
\text { dalam } \\
\text { mencari } \\
\text { ukuran }\end{array}$ \\
\hline
\end{tabular}




\begin{tabular}{|c|c|c|c|c|c|c|}
\hline & & & & & & $\begin{array}{l}\text { estimasi } \\
\text { makanan } \\
\text { Beberapa } \\
\text { responden } \\
\text { mengatakan } \\
\text { motivasi diri } \\
\text { juga } \\
\text { berpengaruh } \\
\text { dalam } \\
\text { program } \\
\text { penurunan } \\
\text { berat badan } \\
\text { menggunaka } \\
\mathrm{n} \text { aplikasi } \\
\end{array}$ \\
\hline $\begin{array}{l}\text { 5. (Mumm } \\
\text { ah et al., } \\
\text { 2017) }\end{array}$ & $\begin{array}{l}\text { Effect Of A } \\
\text { Mobile App } \\
\text { Intervention } \\
\text { On Vegetable } \\
\text { Consumption } \\
\text { In } \\
\text { Overweight } \\
\text { Adults: A } \\
\text { Randomized } \\
\text { Controlled } \\
\text { Trial }\end{array}$ & $\begin{array}{l}\text { Internatio } \\
\text { nal } \\
\text { Journal } \\
\text { of } \\
\text { Behavior } \\
\text { al } \\
\text { Nutrition } \\
\text { and } \\
\text { Physical } \\
\text { Activity }\end{array}$ & $\begin{array}{l}\text { Menilai dengan } \\
\text { seksama } \\
\text { keefektifan } \\
\text { aplikasi seluler } \\
\text { "Vegethon" } \\
\text { diantar sampel } \\
\text { orang dewasa } \\
\text { yang kelebihan } \\
\text { berat badan yang } \\
\text { berusaha } \\
\text { melakukan } \\
\text { pemeliharaan } \\
\text { penurunan berat } \\
\text { badan }\end{array}$ & $\begin{array}{l}\text { Randomized } \\
\text { Controlled } \\
\text { Trials }\end{array}$ & 2. & $\begin{array}{l}\text { Hasil } \\
\text { penelitian } \\
\text { ini } \\
\text { menunjukan } \\
\text { keefektifan } \\
\text { penggunaan } \\
\text { aplikasi } \\
\text { "Vegheton" } \\
\text { sama } \\
\text { dengan haisl } \\
\text { penelitian } \\
\text { sebelumnya. } \\
\text { Hasil } \\
\text { penelitian } \\
\text { menunjukan } \\
\text { aplikasi ini } \\
\text { efektif } \\
\text { dalam } \\
\text { peningkatan } \\
\text { konsumsi } \\
\text { sayuran } \\
\text { pada klien } \\
\text { dewasa } \\
\text { dengan } \\
\text { obesitas. } \\
\text { Pembuat } \\
\text { kebijakan } \\
\text { diharapkan } \\
\text { mengemban } \\
\text { gkan } \\
\text { aplikasi } \\
\text { dengan } \\
\text { biaya yang } \\
\text { murah agar }\end{array}$ \\
\hline
\end{tabular}




\begin{tabular}{|c|c|c|c|c|c|c|}
\hline & & & & & & $\begin{array}{l}\text { dapat } \\
\text { digunakan } \\
\text { bagi klien } \\
\text { yang ingin } \\
\text { menurunkan } \\
\text { berat badan }\end{array}$ \\
\hline 6. & $\begin{array}{l}\text { (Turner- } \\
\text { McGrie } \\
\text { vy et al., } \\
2019 \text { ) }\end{array}$ & $\begin{array}{l}\text { Defining } \\
\text { Adherence to } \\
\text { Mobile } \\
\text { Dietary Self- } \\
\text { Monitoring } \\
\text { and Assessing } \\
\text { Tracking } \text { Over } \\
\text { Time: } \\
\text { Tracking at } \\
\text { Least Two } \\
\text { Eating } \\
\text { Occasions per } \\
\text { Day Is Best } \\
\text { Marker of } \\
\text { Adherence } \\
\text { within Two } \\
\text { Different } \\
\text { Mobile Health } \\
\text { Randomized } \\
\text { Weight Loss } \\
\text { Interventions }\end{array}$ & $\begin{array}{l}\text { Journal } \\
\text { of the } \\
\text { academy } \\
\text { of } \\
\text { nutrition } \\
\text { and } \\
\text { dietetics }\end{array}$ & $\begin{array}{l}\text { Mengidentifikasi } \\
\text { kriteria terbaik } \\
\text { untuk } \\
\text { mendefiniskan } \\
\text { kepatuhan } \\
\text { terhadap } \\
\text { pemantauan diri } \\
\text { sendiri dengan } \\
\text { perangkat seluler } \\
\text { dalam } \\
\text { memprediksi } \\
\text { penurunan berat } \\
\text { badan }\end{array}$ & $\begin{array}{l}\text { Randomized } \\
\text { Controlled } \\
\text { Trials }\end{array}$ & $\begin{array}{l}\text { 1. Hasil } \\
\text { menunjukan } \\
\text { responden } \\
\text { yang } \\
\text { menggunakan } \\
\text { aplikasi } \\
\text { setidaknya } \\
\text { dua kali } \\
\text { makan dapat } \\
\text { menurunkan } \\
\text { berat badan } \\
\text { 0,09 kg. } \\
\text { 2. Penggunaan } \\
\text { kriteria } \\
\text { jumlah hari } \\
\text { setidaknya } \\
\text { dua kali } \\
\text { makan, } \\
\text { dilacak paling } \\
\text { baik dan } \\
\text { diprediksi } \\
\text { terjadi } \\
\text { penurunan } \\
\text { berat badan } \\
\text { pada } 6 \text { bulan } \\
\text { ketika } \\
\text { menggunakan } \\
\text { m-health } \\
\text { yang berbeda } \\
\text { digabungkan } \\
\text { 3. Metode } \\
\text { pemantauan } \\
\text { mandiri } \\
\text { mobile diet } \\
\text { cara yang } \\
\text { efektif bagi } \\
\text { pengguna } \\
\text { dalam } \\
\text { mengatur } \\
\text { berat badan }\end{array}$ \\
\hline 7. & $\begin{array}{l}\text { (Fakih } \\
\text { El }\end{array}$ & $\begin{array}{l}\text { The Effects of } \\
\text { Dietary }\end{array}$ & $\begin{array}{l}\text { Journal } \\
\text { of the }\end{array}$ & $\begin{array}{l}\text { Menilai } \\
\text { keefektifan }\end{array}$ & $\begin{array}{l}\text { Systematic } \\
\text { review }\end{array}$ & $\begin{array}{l}\text { Temuan dari } \\
\text { sistematik }\end{array}$ \\
\hline
\end{tabular}




\begin{tabular}{|c|c|c|c|c|c|c|}
\hline & $\begin{array}{l}\text { Khoury } \\
\text { et al., } \\
\text { 2019) }\end{array}$ & $\begin{array}{l}\text { Mobile Apps } \\
\text { on Nutritional } \\
\text { Outcomes in } \\
\text { Adults with } \\
\text { Chronic } \\
\text { Diseases: A } \\
\text { Systematic } \\
\text { Review and } \\
\text { Meta-Analysis } \\
\text { Cosette }\end{array}$ & $\begin{array}{l}\text { academy } \\
\text { of } \\
\text { nutrition } \\
\text { and } \\
\text { dietetics }\end{array}$ & \begin{tabular}{l}
\multicolumn{2}{l}{ penggunaan } \\
aplikasi seluler \\
makanan pada \\
gizi klien dewasa \\
dengan penyakit \\
kronis
\end{tabular} & $\begin{array}{l}\text { PRISMA } \\
\text { (Preferred } \\
\text { Reporting } \\
\text { Items for } \\
\text { Systematic } \\
\text { Reviews and } \\
\text { Meta- } \\
\text { Analyses) }\end{array}$ & $\begin{array}{l}\text { review ini bahwa } \\
\text { aplikasi seleluler } \\
\text { untuk diet adalah } \\
\text { alat pemantauan } \\
\text { mandiri yang } \\
\text { efektif dan } \\
\text { aplikasi ini } \\
\text { menghasilkan } \\
\text { efek positif pada } \\
\text { hasil gizi yang } \\
\text { diukur pada } \\
\text { penyakit kronis, } \\
\text { yaitu penurunan } \\
\text { berat badan. }\end{array}$ \\
\hline 8. & $\begin{array}{l}\text { (Wipfli } \\
\text { et al., } \\
\text { 2019) }\end{array}$ & $\begin{array}{l}\text { Process } \\
\text { Evaluation of } \\
a \quad \text { Mobile } \\
\text { Weight Loss } \\
\text { Intervention } \\
\text { for Truck } \\
\text { Drivers }\end{array}$ & $\begin{array}{l}\text { Journal } \\
\text { Safety and } \\
\text { Health at } \\
\text { Work }\end{array}$ & \begin{tabular}{l}
\multicolumn{2}{l}{ Mengevaluasi } \\
dampak relatif \\
dari komponen \\
intervensi pada \\
hasil $r$ studi \\
dianatar peseserta \\
dalam kondisi \\
intervensi yang \\
melaporkan \\
penilaian \\
kesehatan pasca \\
intervensi untuk \\
mendorong \\
adopsi taktik dan \\
menginformasika \\
n replikasi \\
dimasa depan, \\
menyesuaikan \\
dan perangkat \\
tambahan
\end{tabular} & $\begin{array}{l}\text { Randomized } \\
\text { Controlled } \\
\text { Trial }\end{array}$ & $\begin{array}{l}\text { 1. Responden } \\
\text { yang } \\
\text { menyelesaika } \\
\mathrm{n} \text { program } \\
\text { menghasilkan } \\
\text { penurunan } \\
\text { berat badan } \\
\text { yang jauh } \\
\text { lebih besar } \\
\text { daripada yang } \\
\text { tidak. } \\
\text { 2. Pemantaun } \\
\text { diri perilaku, } \\
\text { pelatihan } \\
\text { berbasis } \\
\text { komputer dan } \\
\text { pembinaan } \\
\text { kesehatan } \\
\text { adalah } \\
\text { prediktor } \\
\text { signifikan } \\
\text { dari } \\
\text { perubahan } \\
\text { diet } \\
\text { 3. Pemantau } \\
\text { mandiri berat } \\
\text { badan dan } \\
\text { perilaku } \\
\text { kesehatan } \\
\text { berbasis web } \\
\text { adalah taktik } \\
\text { cara yang } \\
\text { sangat efektif } \\
\text { dalam }\end{array}$ \\
\hline
\end{tabular}




\begin{tabular}{|c|c|c|c|c|c|c|}
\hline & & & & & & $\begin{array}{l}\text { intervensi } \\
\text { M.health }\end{array}$ \\
\hline 9. & $\begin{array}{l}\text { (Alnuai } \\
\text { mi, } \\
\text { Rawaf, } \\
\text { Hassoun } \\
\text { ah, \& } \\
\text { Chehab, } \\
\text { 2019)us }\end{array}$ & $\begin{array}{l}\text { Use of mobile } \\
\text { applications in } \\
\text { the } \\
\text { management } \\
\text { of overweight } \\
\text { and obesity in } \\
\text { primary and } \\
\text { secondary } \\
\text { care }\end{array}$ & $\begin{array}{l}\text { Journal } \\
\text { of the } \\
\text { Royal } \\
\text { Society of } \\
\text { Medicine } \\
\text { Open }\end{array}$ & $\begin{array}{l}\text { 1. Mengevaluasi } \\
\text { penggunaan } \\
\text { aplikasi dalam } \\
\text { mengelola } \\
\text { berat badan } \\
\text { pada klien } \\
\text { obesitas oleh } \\
\text { petugas } \\
\text { kesehatan di } \\
\text { sekolah dasar } \\
\text { 2. Menilai klien } \\
\text { dan petugas } \\
\text { perawatan } \\
\text { kesehatan } \\
\text { setelah } \\
\text { penggunaan } \\
\text { aplikasi } \\
\text { 3. Mengevaluasi } \\
\text { kepuasan } \\
\text { klien dan } \\
\text { dokter }\end{array}$ & $\begin{array}{l}\text { Systematic } \\
\text { review }\end{array}$ & $\begin{array}{l}\text { Menunjukkan } \\
\text { bahwa aplikasi } \\
\text { seleluer } \\
\text { memiliki } \\
\text { potensi untuk } \\
\text { memfasilitasi } \\
\text { pengelolan } \\
\text { manajemen } \\
\text { berat badan. }\end{array}$ \\
\hline 10 & $\begin{array}{l}\text { (Wang, } \\
\text { Xue, } \\
\text { Huang, } \\
\text { Huang, } \\
\& \\
\text { Zhang, } \\
2017 \text { ) }\end{array}$ & $\begin{array}{l}\text { A Systematic } \\
\text { Review of } \\
\text { Application } \\
\text { and } \\
\text { Effectiveness } \\
\text { of mHealth } \\
\text { Interventions } \\
\text { for Obesity } \\
\text { and Diabetes } \\
\text { Treatment and } \\
\text { Self- } \\
\text { Management }\end{array}$ & $\begin{array}{l}\text { Journal } \\
\text { American } \\
\text { Society } \\
\text { for } \\
\text { Nutrition }\end{array}$ & $\begin{array}{l}\text { 1. Menilai dan } \\
\text { meneliti } \\
\text { efektivitas } \\
\text { intervensi m- } \\
\text { Health untuk } \\
\text { obesitas dan } \\
\text { perawatan } \\
\text { manajemen } \\
\text { diabetes } \\
\text { 2. Mengidentifik } \\
\text { asi } \\
\text { kesenjangan } \\
\text { literatur dan } \\
\text { emmberikan } \\
\text { rekomendasi } \\
\text { untuk masa } \\
\text { depan }\end{array}$ & $\begin{array}{l}\text { Systematic } \\
\text { review }\end{array}$ & $\begin{array}{l}\text { 1. Dengan studi } \\
\text { kualitatif ada } \\
\text { pengaruh } \\
\text { intervensi m- } \\
\text { health } \\
\text { terhadap } \\
\text { obesitas } \\
\text { 2. Dengan studi } \\
\text { kuantitatif } \\
\text { ada pengaruh } \\
\text { yang } \\
\text { signifikan m- } \\
\text { health } \\
\text { intervensi } \\
\text { untuk } \\
\text { manajemen } \\
\text { obesitas }\end{array}$ \\
\hline
\end{tabular}

\section{PEMBAHASAN}

Salah satu penyebab kematian saat ini adalah masalah kesehatan seseorang. Indikator seseorang sehat dilihat dari aktivitas fisik, overweight \& obesitas, merokok, penggunaan obat-obatan, kesehatan jiwa, cidera / kekerasan, kulitas lingkungan, imunisasi, respon perilaku seksual, akses pelayanan kesehatan (Edelman \& Mandhle, 2010).

Obesitas dan overweight merupakan gangguan kesehatan karena adanya penumpukan lemak 
yang berlebihan didalam pembuluh darah sehingga dapat menyebabkan gangguan vaskular berupa sumbatan. Gangguan obesitas akibat dari perilaku kesehatan yang negatif. Perilaku kesehatan mempengaruhi tindakan dalam memproteksi diri (Edelman \& Mandhle, 2010).

Sehingga dalam upaya mengurangi masalah gangguan berat badan maka klien dan tenaga kesehatan perlu melakukan perubahan perilaku. Salah satu intervensi yang membantu perubahan perilaku adalah melakukan promosi kesehatan. Salah satunya adalah membuat mobile application untuk membantu dalam memberikan pelayanan kesehatan (Lieffers et al., 2018).

Beberapa aplikasi dalam tinjauan literatur merupakan aplikasi yang ditujukan untuk mengatur pola makan untuk mencegah dan membantu menurunkan masalah kelebihan berat badan ( overweight) dan obesitas (Lieffers et al., 2018). Aplikasi ini ditujukan bagi pengguna smartphone terutama orang dewasa. Contoh aplikasi yang bisa digunakan dalam mengatur pola makan adalah Vegethon, CHAT, MyFitnessPal App. Isi dalam aplikasi ini berupa informasi mulai dari memberikan cara pengaturan makan, informasi tentang makanan yang baik (seperti sayuran, buah, dan menu lain), tanda biologis dalam kebutuhan makanan seperti kandungan garam dalam tubuh, serta ada umpan balik dalam intervensi yang diberikan.

Aplikasi ini dibuat menarik dengan memberikan visual yang sesuai dan salah satu aplikasi bisa digunakan untuk memantau kepatuhan diri dalam melakukan pengaturan pola makan. Semua aplikasi ini untuk menanamkan keyakinan bahwa penting seseorang mengatur pola makan. Dari masalah pola makan maka akan berdampak pada kesehatan. Penyakit yang timbul adalah penyakit tidak menular (non communicable diseases) seperti penyakit kardiovakuler, hipertensi, diabetes, osteoarthritis, dan lainya. Sehingga dengan adanya teknologi yang mampu memberikan kontribusi dalam hal kesehatan, akan meningkatkan angka harapan hidup yang lebih lama.

Kelebihan dalam penggunaan aplikasi berbasis mobile adalah memberikan informasi tentang diet yang baik dan cara pengaturan dan memantau kepatuhan diet sehingga dapat mencegah obesitas dan overweight, efektif, dan bisa dilakukan dimana saja, dan mudah dalam akses informasi. Sedangkan kekurangan dalam penggunaan aplikasi berbasis mobile adalah belum ada pembuat kebijakan yang menggunakan model aplikasi ini untuk dapat disebar luaskan agar mempermudah dalam penggunaan dengan biaya yang murah sehingga dapat digunakan secara merata sebagai alat untuk promosi kesehatan.

\section{KESIMPULAN}

Perkembangan teknologi industri 4.0 berbasis internet, memberikan perkembangan dalam dunia kesehatan salah satunya adalah keperawatan. Penciptaan teknologi memudahkan seseorang mengakses informasi lebih cepat dan lebih banyak. Beberapa contoh mobile application dalam intervensi mencegah dan menurunkan berat badan adalah CHAT, Vegethon, MyFitnessPal App yang memiliki fungsi sebagai alat bantu dalam mengatur diet atau pola makan seseorang. Sasaran yang digunakan adalah usia dewasa, karena potensi tinggi mengalami obesitas dan 
penggunaan seluler (smartphone) yang tinggi.

Mobile application bertujuan untuk mengatur diet pada seseorang perlu adanya penelitian yang lebih lanjut dan mendalam tentang keefektifan intervensi mobile application untuk diet. Memperjelas hubungan terapeutik aplikasi ini dengan pengguna sehingga tujuan mencapai indikator sehat bebas dari obesitas dan kelebihan berat badan terlaksana dan lebih signifikan.

Penggunaan teknologi mobile application bisa memberikan intervensi keperawatan dalam memberikan promosi kesehatan tentang diet yang baik dan benar, dengan biaya terjangkau, akses informasi lebih banyak dan lebih cepat. Perawat dapat mengaplikasikan dalam praktik keperawatan komunitas dan mengembangkan aplikasi dalam penelitian keperawatan.

\section{DAFTAR PUSTAKA}

Alnuaimi, A., Rawaf, S., Hassounah, S., \& Chehab, M. (2019). Use of Mobile Applications in The Management of Overweight and Obesity in Primary and Secondary care. Journal of the Royal Society of Medicine, 10(3), 1-8. Retrieved from https://www.ncbi.nlm.nih.gov/pm c/articles/PMC6452595/pdf/10.1 177_2054270419843826.pdf

Edelman, C. L., \& Mandhle, C. lyn. (2010). Health Promotion Through the Life Span. In NUrsing (7th ed., pp. 479-544). St. Louis, Missouri: Mos.

Fakih El Khoury, C., Karavetian, M., Halfens, R. J. G., Crutzen, R., Khoja, L., \& Schols, J. M. G. A. (2019). The Effects of Dietary Mobile Apps on Nutritional Outcomes in Adults with Chronic
Diseases: A Systematic Review and Meta-Analysis. Journal of the Academy of Nutrition and Dietetics, 119(4), 626-651. https://doi.org/10.1016/j.jand.201 8.11 .010

Hingle, M., \& Patrick, H. (2016). There Are Thousands of Apps for That: Navigating Mobile Technology for Nutrition Education and Behavior. Journal of Nutrition Education and Behavior, 48(3), 213-218.e1. https://doi.org/10.1016/j.jneb.201 5.12.009

Ipjian, M. L., \& Johnston, C. S. (2017). Smartphone Technology Facilitates Dietary Change In Healthy Adults. Nutrition, 33, 343-347.

https://doi.org/10.1016/j.nut.2016 .08 .003

Kerr, D. A., Harray, A. J., Pollard, C. M., Dhaliwal, S. S., Delp, E. J., Howat, P. A., ... Boushey, C. J. (2016). The Connecting Health And Technology Study: A 6Month Randomized Controlled Trial To Improve Nutrition Behaviours Using A Mobile Food Record And Text Messaging Support In Young Adults. International Journal of Behavioral Nutrition and Physical Activity, 13(1), 1-14. https://doi.org/10.1186/s12966016-0376-8

Lieffers, J. R. L., Arocha, J. F., Grindrod, K., \& Hanning, R. M. (2018). Experiences and Perceptions of Adults Accessing Publicly Available Nutrition Behavior-Change Mobile Apps for Weight Management. Journal of the Academy of Nutrition and Dietetics, 118(2), 229-239.e3. https://doi.org/10.1016/j.jand.201 7.04.015 
Mummah, S., Robinson, T. N., Mathur, M., Farzinkhou, S., Sutton, S., \& Gardner, C. D. (2017). Effect Of A Mobile App Intervention On Vegetable Consumption In Overweight Adults: A Randomized Controlled Trial. International Journal of Behavioral Nutrition and Physical Activity, 14(1), 111.

https://doi.org/10.1186/s12966017-0563-2

RISKESDAS. (2018). Hasil Utaman RSIKESDAS 2018. Jakarta.

Sindu, K. (2018, September). Revolusi Industri 4.0 Dalam Dunia Kesehatan. Sindonews.Com. Retrieved from https://nasional.sindonews.com/re $\mathrm{ad} / 1337174 / 18 /$ revolusi-industri40-dalam-dunia-kesehatan1536571793

Turner-McGrievy, G. M., Dunn, C. G., Wilcox, S., Boutté, A. K., Hutto, B., Hoover, A., \& Muth, E. (2019). Defining Adherence to Mobile Dietary Self-Monitoring and Assessing Tracking Over Time: Tracking at Least Two Eating Occasions per Day Is Best Marker of Adherence within Two Different Mobile Health Randomized Weight Loss Interventions. Journal of the Academy of Nutrition and Dietetics, 119(9), 1516-1524. https://doi.org/10.1016/j.jand.201 9.03.012

Wang, Y., Xue, H., Huang, Y., Huang, L., \& Zhang, D. (2017). A
Systematic Review of Application and Effectiveness of mHealth Interventions for Obesity and Diabetes Treatment and Self-Management. Journal American Society for Nutrition, 6 , 449-462. Retrieved from https://watermark.silverchair.com / WHO. (2018). Obesity and overweight. Retrieved from WHO website: https://www.who.int/en/newsroom/fact-sheets/detail/obesityand-overweight

WHO. (2019). Reducing Free Sugars Intake In Adults To Reduce The Risk Of Noncommunicable Diseases. Retrieved from eLibrary of Evidence for Nutrition Actions (eLENA) website: https://www.who.int/elena/titles/f ree-sugars-adults-ncds/en/

Wipfli, B., Hanson, G., Anger, K., Elliot, D. L., Bodner, T., Stevens, V., \& Olson, R. (2019). Process Evaluation of a Mobile Weight Loss Intervention for Truck Drivers. Safety and Health at Work, 10(1), 95-102. https://doi.org/10.1016/j.shaw.20 18.08.002

Yanuar, Y. (2019). Survei Kepemilikan Smartphone, Indonesia Peringkat ke-24. Retrieved from Tempo.co website: https://tekno.tempo.co/read/1181 645/survei-kepemilikansmartphone-indonesia-peringkatke-24/full\&view $=$ ok 